\title{
Production of angiotensin converting enzyme by rheumatoid synovial membrane
}

\author{
Douglas Veale, Ghada Yanni, Barry Bresnihan, Oliver FitzGerald
}

\begin{abstract}
Vascular proliferation and mononuclear cell infiltration are prominent changes observed in synovium from actively inflamed joints of patients with rheumatoid arthritis. Angiotensin converting enzyme (ACE) is a halide activated peptidase produced mainly by endothelial cells and by activated monocytes. It has been proposed that levels of ACE activity in synovial fluid might reflect changes in membrane vascularity, the degree of monocyte infiltration, or the thickness of the lining layer. In this study, ACE activity in serum and synovial fluid samples from 18 patients with inflammatory arthritis was measured and compared with levels in 12 control subjects with non-inflammatory arthritis. Although serum levels were similar in the two groups, ACE activity in synovial fluid was significantly increased in the group with inflammatory arthritis compared with controls (mean (SE) 37 (5) $v 19$ (3)). Staining of synovial membranes from patients with rheumatoid arthritis with a monoclonal antibody to ACE localised ACE to the endothelium and to mononuclear cells of macrophage origin. ACE activity was then measured in supernatants of synovial membrane from patients with rheumatoid arthritis after one and seven days of culture. A significant increase in ACE activity was observed after seven days of culture (mean (SE) day 1, 17 (5) $v$ day 7, 25 (3)). Levels of ACE activity, however, did not correlate with the lining layer thickness, with the number of macrophages per square millimetre, nor with the number of blood vessels per square millimetre of synovial tissue. No correlation was observed either between levels of ACE in the supernatant of synovial membrane and levels of interleukin 1 or interleukin 6.

In conclusion, ACE is produced by the synovial membrane of patients with rheumatoid arthritis and is localised to monocytes and endothelial cells. Levels of activity do not directly reflect membrane vascularity, monocyte or macrophage number, or the thickness of the lining layer.
\end{abstract}

Rheumatoid arthritis, is a chronic inflammatory disease characterised histologically by hyperplasia of the synovial lining cells and an intense mononuclear cell infiltrate which may form aggregates. The importance of cells of monocyte or macrophage origin in the pathogenesis of the disease has been highlighted in particular as most of the cytokines which appear to be of importance in rheumatoid arthritis are derived from these cells. ${ }^{1}$ More recently, attention has focused on vascular changes in the synovium. ${ }^{2}$ In a previous study, the vascular changes were quantified and an increase in vessel numbers as well as a change in vessel morphology was observed in synovial membranes obtained from clinically affected joints of patients with early rheumatoid arthritis compared with synovium from clinically unaffected joints and from normal controls at necropsy. ${ }^{3}$ These findings conflict with the report by Stevens $e t a l$, which suggested reduced vascularity with advanced disease ${ }^{4}$ It might be suggested that these differences reflect stages in disease progression. In a further study, however, the number of vessels and vascular morphology in synovial membrane obtained from patients with rheumatoid arthritis, by needle biopsy and at arthroplasty, were examined and no difference between those with early or late disease was observed. ${ }^{5}$ It has been suggested that some of the disease modifying antirheumatic drugs may act by inhibiting macrophage function or by reducing vascular proliferation. ${ }^{6-8}$ Thus it would be of interest to examine the effects of treatment with these drugs on the histological features of synovial membrane.

As the repeated taking of synovial biopsy samples might prove unacceptable for many patients, a readily detectable marker of monocyte function and vascularity in synovial fluid samples would be useful. Angiotensin converting enzyme (ACE) produced mainly by endothelial cells ${ }^{9}$ and by activated monocytes, ${ }^{10}$ might be such a marker. In this study, ACE activity was measured in serum and synovial fluid samples obtained from patients with inflammatory and non-inflammatory joint disease. The localisation of ACE in synovial membranes from patients with rheumatoid arthritis was also examined using a monoclonal antibody to ACE. ACE activity was also measured in the synovial fluid of patients with rheumatoid arthritis undergoing arthroplasty and in the supernatants derived from their synovial membrane cultures. Levels of ACE activity in the synovial fluid and in the supernatants were correlated with the immunohistological features of the synovial membrane and with interleukin 1 and interleukin 6 production in the synovial membrane.

\section{Materials and methods}

PATIENTS

Concomitant samples of serum and synovial fluid were taken from the knees of patients with inflammatory arthritis and from patients with 
non-inflammatory knee effusions. The group with inflammatory arthritis included patients with rheumatoid arthritis, as defined by the revised American College of Rheumatology criteria, ${ }^{11}$ reactive arthritis, seronegative rheumatoid arthritis, gout, and systemic lupus erythematosus. The group with non-inflammatory arthritis was composed of patients with osteoarthritis and patients undergoing arthroscopy for traumatic knee injury. In the second part of the study, synovial fluid and synovium samples were obtained at arthroplasty from a further group of patients with seropositive rheumatoid arthritis.

Blood and synovial fluid samples were taken in plain tubes and centrifuged. All samples of serum and centrifuged synovial fluid were then stored at $-20^{\circ} \mathrm{C}$ until analysed. Blood samples were also analysed for haemoglobin, erythrocyte sedimentation rate (Westergren), and rheumatoid factor (latex fixation).

ACE ASSAY

ACE activity was measured in all samples using a two point kinetic assay based on the method of Holmquist et al. ${ }^{12}$ The assay reagents were available in a kit produced by Sigma Diagnostics (Poole, Dorset, UK) and the ACE activity was determined using a fully automated spectrophotometer (Abbott, ABA-100) with detection at $340 \mathrm{~nm}$. The assay was reproducible with an intra-assay variation of $5 \mathrm{U} / \mathrm{ml}$. One freeze/thaw cycle did not alter the ACE activity in the serum or centrifuged synovial fluid samples.

\section{IMMUNOHISTOLOGICAL STUDIES}

Synovial membrane obtained at arthroplasty was snap frozen in isopentane and liquid nitrogen before storage at $-70^{\circ} \mathrm{C}$ until sectioning. Cryostat sections $7 \mu \mathrm{m}$ thick were cut at $-20^{\circ} \mathrm{C}$, placed on gelatin coated glass slides and allowed to dry at room temperature. The sections were fixed in acetone for 10 minutes and were then washed in phosphate buffered saline before incubation with the primary antisera for one hour. The table shows the monoclonal antibodies used.

The sections were stained using a routine three stage immunoperoxidase technique. ${ }^{1314}$ This allowed quantification of the various cell types (expressed as number of cells per square millimetre) including $T$ lymphocyte subpopulations and macrophages as well as membrane vascularity (expressed as number of vessels per square millimetre).

Monoclonal antibodies and their specificities

\begin{tabular}{|c|c|c|c|}
\hline Antibody & Antigen & Specificity & Source \\
\hline $\begin{array}{l}\text { Leu } 1 \\
\text { Leu 2a }\end{array}$ & $\begin{array}{l}\text { CD5 } \\
\text { CD8 }\end{array}$ & $\begin{array}{l}\text { T cells } \\
\text { Suppressor/cytotoxic } \\
\text { T cells }\end{array}$ & $\begin{array}{l}\text { Becton Dickenson } \\
\text { Becton Dickenson }\end{array}$ \\
\hline $\begin{array}{l}\text { Leu 3a } \\
\text { UCHL1 } \\
\text { Leu } 14 \\
\text { MO2 } \\
\text { Antibody to ACE }\end{array}$ & $\begin{array}{l}\text { CD4 } \\
\text { CD45Ro } \\
\text { CD22 } \\
\text { CD14 } \\
\text { ACE }\end{array}$ & $\begin{array}{l}\text { Helper/inducer T cells } \\
\text { Memory T cells } \\
\text { B cells } \\
\text { Monocyte/macrophages } \\
\text { Angiotensin converting } \\
\text { enzyme }\end{array}$ & $\begin{array}{l}\text { Becton Dickenson } \\
\bar{B}^{*} \\
\text { Becton Dickenson } \\
\text { Becton Dickenson } \\
-\dagger\end{array}$ \\
\hline Antibody to FVIII & FVIIIRag & Endothelium & Dako \\
\hline
\end{tabular}

*A gift from Professor P Beverley, University College Hospital, London, UK.

tA gift from Professor R Auerbach, University of Wisconsin, USA.
SYNOVIAL MEMBRANE CULTURES

Undigested synovial membrane $(0.25 \mathrm{~g})$, dissected free of tendinous and adipose tissue, was cultured in $1.25 \mathrm{ml}$ of RPMI (Gibco, Paisley, UK) containing $10 \%$ fetal calf serum (Panox, Antrim, UK), $1 \%$ glutamine (Gibco), $1.8 \mu \mathrm{g} / \mathrm{ml}$ amphotericin, and $50 \mu \mathrm{g} / \mathrm{ml}$ gentamicin (Gibco) in sterile flat bottomed multiwell tissue culture plates. Following incubation at $37^{\circ} \mathrm{C}$ in a humidified atmosphere with $5 \% \mathrm{CO}_{2}$, the tissue supernatants were harvested at days 1 and 7 for the determination of cytokines and ACE activity. Interleukin 1 and interleukin 6 were determined by radioimmunoassay.

\section{STATISTICAL ANALYSIS}

Differences between paired data were analysed using the Wilcoxon signed rank test or the Mann-Whitney $U$ test. The significance of correlations was determined using the Spearman rank correlation test.

\section{Results}

\section{CLINICAL FEATURES}

Of the 18 patients in the group with inflammatory arthritis, 13 had seropositive rheumatoid arthritis, one seronegative rheumatoid arthritis, two reactive arthritis, and one each gout and systemic lupus erythematosus. The group with non-inflammatory arthritis was composed of 12 patients, seven with osteoarthritis, and five with traumatic knee injury. There were 13 women and five men with a mean age of 47 years (range 17-80) in the group with inflammatory arthritis and there were 10 men and two women with a mean age of 48 years (range 24-71) in the control group. The patients

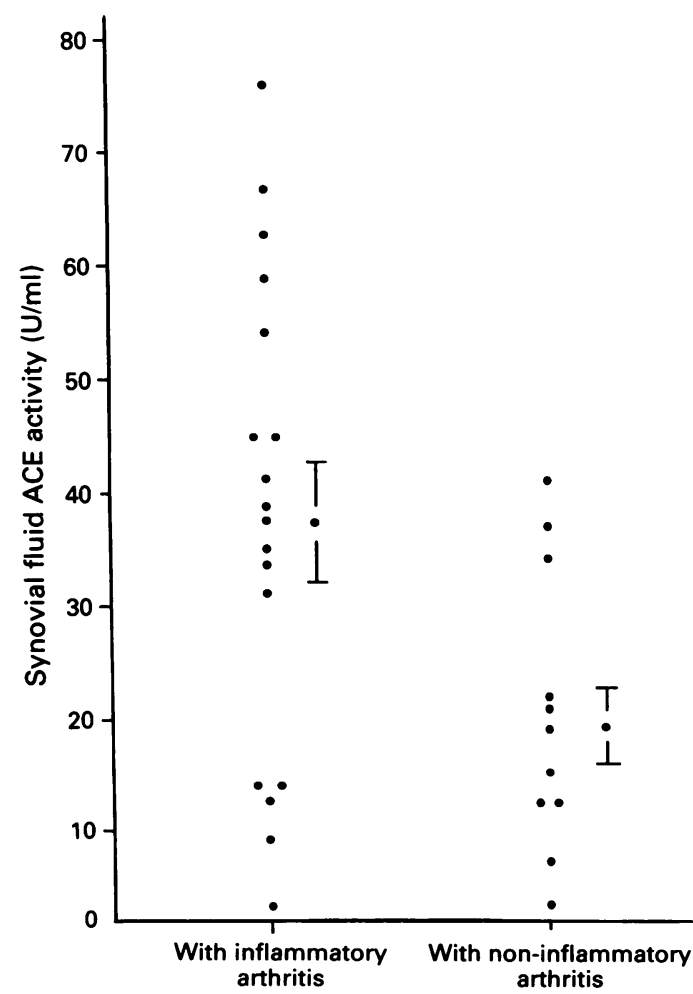

Figure 1 Mean $(S E)$ activity of angiotensin converting enzyme $(A C E)$ in synovial fluid from patients with inflammatory and non-inflammatory arthritis. 
in the two groups were receiving a variety of non-steroidal anti-inflammatory drugs and six of the patients with rheumatoid arthritis were also receiving disease modifying drugs. No patients had received intra-articular corticosteroids within three months of the study.

\section{ACE IN SERUM AND SYNOVIAL FLUID}

Although serum ACE levels tended to be higher in the group with inflammatory arthritis compared with the controls, no statistically significant difference was observed. In contrast, the mean (SE) ACE activity $(\mathrm{U} / \mathrm{ml})$ in the synovial fluid of the group with inflammatory arthritis was 37 (5) which was significantly greater than that in the group with non-inflammatory arthritis (19 (3); $\mathrm{p}<0.05$ ) (fig 1). In addition, 10 of $18(55 \%)$ of the group with inflammatory arthritis compared with two of 12 $(16 \%)$ of the non-inflammatory controls had higher levels of ACE activity in synovial fluid than in serum samples, although the difference was not statistically significant. Furthermore, ACE activity in synovial fluid from the group with inflammatory arthritis did not correlate with rheumatoid factor positivity, disease activity, or the use of disease modifying agents.

LOCALISATION OF ACE IN SYNOVIAL MEMBRANE FROM PATIENTS WITH RHEUMATOID ARTHRITIS Synovial membrane samples obtained at arthroplasty from patients with rheumatoid arthritis were stained with a monoclonal antibody to ACE. Analysis of samples showed that the ACE was localised to the luminal surface of the endothelial cell membrane and to mononuclear cells in the stroma and the lining layer (fig 2). The mononuclear cells were identified as macrophages by staining serial sections with

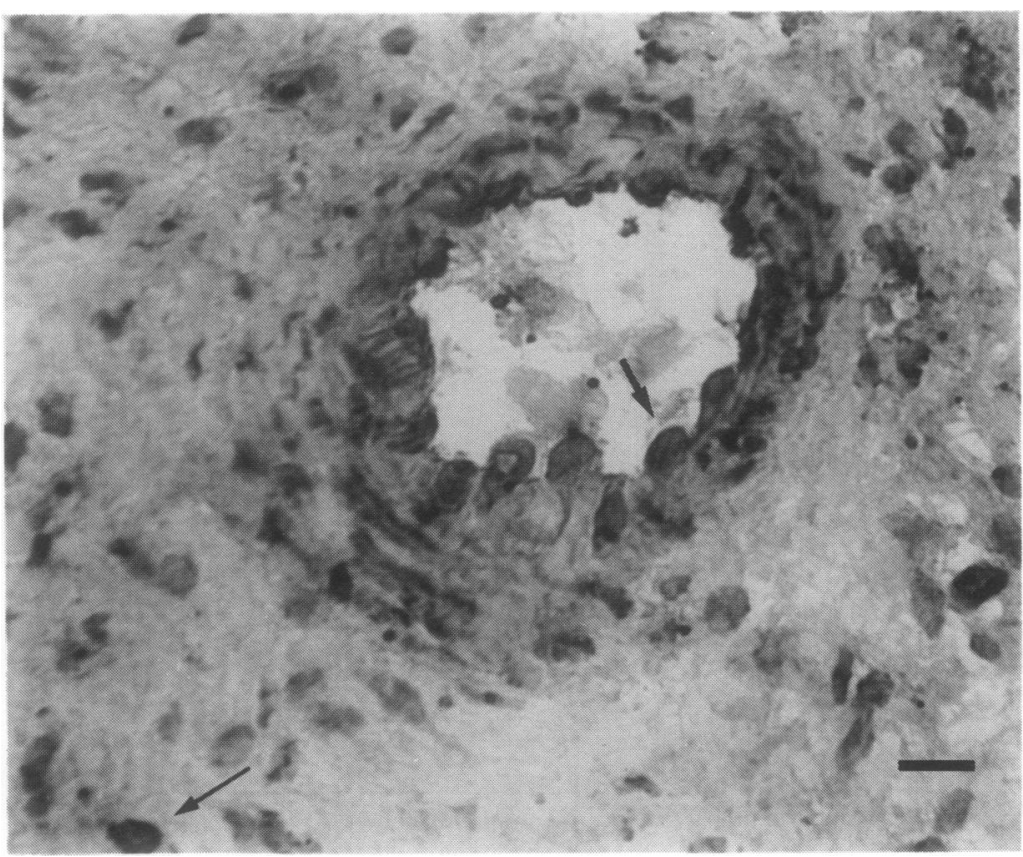

Figure 2 Rheumatoid synovial membrane stained with a monoclonal antibody to ACE shows staining of the luminal surface of the endothelium (thick arrow) and monocytel macrophage cells (thin arrow) of the stroma. Bar $=2.5 \mathrm{~mm}$ (immunoperoxidase stain).

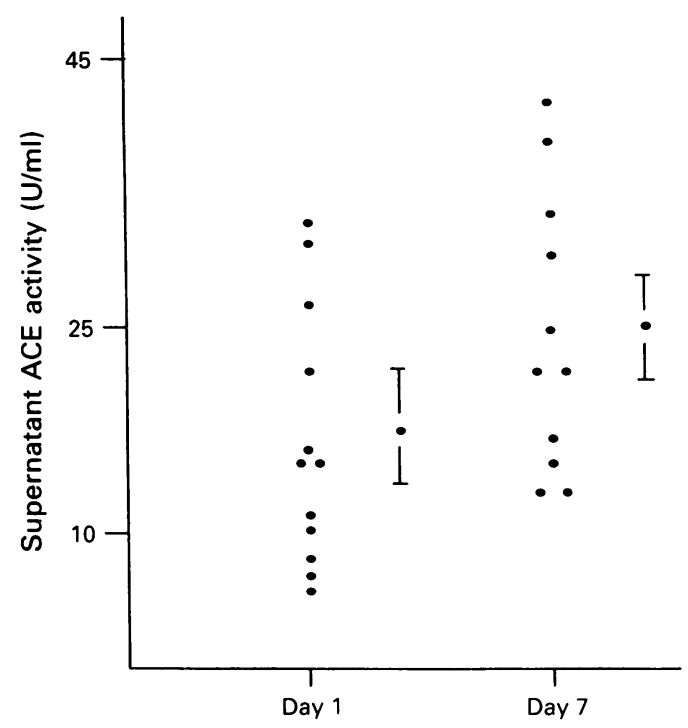

Figure 3 Mean $(S E)$ activity of angiotensin converting enzyme $(A C E)$ in supernatants taken on days 1 and 7 from synovial membrane cultures.

antibody to $\mathrm{ACE}$ and the $\mathrm{CD} 14$ monocyte marker.

\section{SYNOVIAL MEMBRANE CULTURES}

The mean (SE) ACE activity in the synovial fluid samples taken at arthroplasty from 12 patients with rheumatoid arthritis was 38 (6). The ACE activity in the synovial membrane culture supernatants at day 1 was $17(5)$ and at day 7 showed a significant increase to 25 (3) $(p=0.05)$ (fig 3). A significant correlation was observed between the ACE activity in synovial fluid and the increase in ACE activity from days 1 to $7(p=0.001)$. Levels of ACE activity at days 1 and 7 showed a significant correlation $(p=$ 0.001).

As ACE is a product of endothelial cells and activated macrophages, attempts were made to correlate ACE activity in the synovial fluid or synovial membrane supernatants with membrane vascularity or macrophage number. No such correlation was observed. The ACE activity did not correlate either with numbers of $T$ cells, $T$ cell subsets, B cells, lining layer thickness, or synovial membrane supernatant levels of interleukin 1 or interleukin 6 .

\section{Discussion}

Angiotensin converting enzyme is a halide activated peptidase which catalyses the release of histidylleucine from the $\mathrm{COOH}$ terminus of the decapeptide angiotensin I to yield a pressor peptide, angiotensin II. $^{9}$ In addition, ACE inactivates bradykinin, an important vasodilator, by catalysing the sequential release of phenylalanine-arginine and serine-proline from the $\mathrm{COOH}$ terminus. ${ }^{15}$ Bradykinin has been shown to be present in synovial fluid in inflammatory arthritis, ${ }^{16}$ to have proinflammatory effects on fibroblasts, ${ }^{17}$ and also leads to stimulation of pain fibres. ${ }^{18}$ This suggests that ACE may have important regulatory functions in the inflammatory process. Using a fluorescein 
labelled antibody, ACE has been localised to the vascular endothelium ${ }^{19}$ and the presence of ACE on cultured endothelial cells has been used as a marker as cultured fibroblasts and smooth muscle cells do not have it. ${ }^{20}$ The control of ACE secretion by the vascular endothelium is uncertain-however, it is of interest that hypoxia has been reported to inhibit ACE and results in a decrease in angiotensin II generation and a decrease in bradykinin degradation. ${ }^{21} 22$

Serum levels of ACE have been found to be increased in a number of diseases, notably sarcoidosis. ${ }^{23}$ The origin of the ACE activity in sarcoidosis is uncertain, but evidence points towards cells of the monocyte/macrophage system. ${ }^{24}$ Considerable numbers of macrophages and monocytes are found within sarcoid granulomas, ${ }^{25}$ and human monocytes in culture can be induced to produce ACE following exposure to dexamethasone. ${ }^{10}$ Serum and synovial fluid levels of ACE have also been measured previously in patients with polyarthritis. ${ }^{26}{ }^{27}$ In one study, although serum levels were similar in patients with rheumatoid arthritis, osteoarthritis, seronegative arthropathy, and in normal controls, synovial fluid ACE activity was higher in patients with rheumatoid arthritis than in those with osteoarthritis, though they were similar when corrected for protein levels. ${ }^{26}$ More recently, ACE activity was assayed in serum free conditioned medium from unstimulated peripheral blood monocytes from patients with rheumatoid arthritis, osteoarthritis, and from normal controls. ${ }^{27}$ The results indicate that monocytes from patients with rheumatoid arthritis, in particular those with early disease, produce more ACE than monocytes from control subjects. That study did not examine the production of ACE by synovial monocytes and did not address the possibility that cells other than monocytes, such as vascular endothelial cells, might synthesise and release ACE in the rheumatoid synovial membrane.

Results from this study confirm that synovial fluid levels of ACE activity are increased in patients with inflammatory joint disease (mostly rheumatoid arthritis) compared with controls with non-inflammatory arthritis. That the synovial membrane actively synthesises ACE is shown by the finding of increased ACE activity in synovial membrane culture supernatants after seven days of culture. Although other factors may affect the concentration of a macromolecule such as ACE in synovial fluid in addition to local production, our results point to an important contribution by synovial membrane secretion. Furthermore, the close correlation $(p=0.001)$ in this study between levels of ACE in synovial fluid and the rate of secretion of ACE by synovial membrane between days 1 and 7 into the culture supernatant shows that local production by the synovial membrane is clearly a major source of ACE in synovial fluid. Using a monoclonal antibody to ACE, we have for the first time localised ACE to the vascular endothelium and to some mononuclear cells in the stroma and lining layer of synovium in patients with rheumatoid arthritis. These cells were identified as cells of the macrophage/monocyte lineage, thus confirming previous observations.
Supernatant levels of ACE, however, do not correlate with any of the immunohistological features or with supernatant levels of the predominantly macrophage derived cytokines, interleukin 1 and interleukin 6. Although these results indicate that ACE activity in synovial fluid does not directly reflect the lining layer thickness, macrophage number, nor membrane vascularity, it could be that ACE production is a function of cell activation rather than cell number.

This is the first study to show the de novo production of ACE in the synovial membrane of patients with rheumatoid arthritis and the localisation of the enzyme to the endothelium and to monocytes. The potential part played by ACE in the inflamed synovial membrane is uncertain, but by increasing the conversion of angiotensin I to angiotensin II and by inactivating bradykinin, ACE would predominantly have a vasopressor effect. This might in turn lead to episodes of tissue hypoxia, which when followed by reperfusion may lead to a release of oxygen free radicals, thought to be important mediators of cell damage in rheumatoid arthritis. $^{28}$

The authors are grateful for the support of The Charitable Infirmary Charitable Trust in funding this project.

1 Firestein G S, Zvaifler N J. How important are T cells in chronic rheumatoid synovitis. Arthritis Rheum 1990; 33: 768-73.

2 Iguchi T, Ziff M. Electron microscopic study of rheumatoid synovial vasculature: intimate relationship between tal endothelium and lymphoid aggregation. $\mathcal{F}$ Clin Invest 1986 77: 355-61.

3 FitzGerald O, Soden M, Yanni G, Robinson R, Bresnihan B. Morphometric analysis of blood vessels in synovial membranes obtained from clinically affected and unaffected knee joints of patients with rheumatoid arthritis. Ann Rheum Dis 1991; 50: 792-6.

4 Stevens C R, Revell A, Blake D R, Levick J R. Synovial vascular morphometry suggests that a state of chronic vascular morphometry suggests that a state of chronic hypoxia exists in the 28 (suppl 2): 62

5 Yanni G, Whelan A, Fieghery C, FitzGerald O, Bresnihan B. Examination of the synovial vascular endothelium in untreated and advanced rheumatoid arthritis. $\mathrm{Br} \mathcal{F} R$ Reumatol 1991; 30 (suppl 1): 7

6 Hirata S, Matsubara T, Saura R, Tateishi H, Hirohata K. Inhibition of in vitro vascular endothelial cell proliferation and in vivo neovascularisation by low-dose methotrexate. Arthritis Rheum 1989; 32: 1065-73.

7 Matsubara T, Ziff M. Inhibition of human endothelial cell proliferation by gold compounds. $\mathcal{F}$ Clin Invest 1987; 79: $1440-6$.

8 Olsen N J, Callahan L F, Pincus T. Immunologic studies of rheumatoid arthritis patients treated with methotrexate. rheumatoid arthritis patients tr.
Arthritis Rheum 1987; 30: 481-8.

9 Studdy P R, Lapworth R, Bird R. Angiotensin-converting enzyme and its clinical significance-a review. $\mathcal{f} C$ lin Pathol 1983; 36: 938-47.

10 Friedland J, Setton C, Silverstein E. Induction of angiotensin converting enzyme in human monocytes in culture. Biochem Biophys Res Commun 1978; 83: 843-9.

11 Arnett F C, Edworthy S M, Bloch D A, et al. The American Rheumatism Association 1987 revised criteria for the classification of rheumatoid arthritis. Arthritis Rheum 1988; 31: 315-24.

12 Holmquist B, Bunning P, Riordan J F. A continuous spectrophotometric assay for angiotensin converting enzyme. Annals of Biochemistry 1979; $95: 540-8$.

13 Hsu S M, Ree H J. Self-sandwich method: an improved immunoperoxidase technique for the detection of small immunoperoxidase technique for the detection of small

14 Hsu S M, Rame L, Fanger H. Use of avidin-biotin peroxidase complex $(\mathrm{ABC})$ in immunoperoxidase tech niques: a comparison between $\mathrm{ABC}$ and unlabelled antibody (PAP) procedures. F Histochem Cytochem 1981 29: $577-80$

$15 \mathrm{Ng} \mathrm{K} \mathrm{K} \mathrm{F}$, Vane J R. Fate of angiotensin I in the circulation. Nature 1968; 218: 144-50.

16 Rahman S, Bunning R A D, Dobson P R M, Brown B L, Aarden L A, Russell R G G. Bradykinin modulates the production of IL-6 and TNF in connective tissue cells by an effect not mediated by prostaglandin E2. Br $\mathcal{F}$ Rheumatol 1989; 28 (suppl 2): 143.

17 Bathon J M, Proud D, Krackow K, Wigley F M. Pre 
incubation of human synovial cells with IL-1 modulates prostaglandin $\mathrm{E}$ release in response to bradykinin. f Immunol 1989; 143: 579-86.

18 Mizmura $\mathrm{K}$, Minagawa M, Tsujii Y, Kumazawa T. The effects of bradykinin agonists and antagonists on visceral
polymodal receptor activities. Pain 1990; 40: 221-7.

19 Ryan J W, Ryan U S, Schultz D R, Whitaker C, Chung A Subcellular localisation of pulmonary angiotensin-conver ing enzyme (Kininase II). Biochem f 1975; 146: 497-9.

20 Caldwell P R B, Seegal B C, Hsu R C, Das M, Soffer R L. Angiotensin converting enzyme-vascular endothelial localisation. Science 1976; 191: 1050-7.

21 Levenburger P J, Stalcup S A, Mellins R B, Greenbaum $\mathrm{L} M$, Turino $\mathrm{G} M$. Decrease in angiotensin I conversion by acute hypoxia in dogs. Proc Soc Exp Biol Med 1978; 158: 586-9.

22 Milledge J S, Catley D M. Renin, aldosterone and converting enzyme during exercise and acute hypoxia in humans. 7 Appl Physiol 1982; 52: 320-3.
23 Liberman J. Elevation of angiotensin convertung enzyme (ACE) level in sarcoidosis. Am F Med 1975; 59: 364-72.

24 Okabe T, Yamagata $K$, Fujisawa $M$, et al. Increased angiotensin converting enzyme in peripheral blood monocytes from patients with sarcoidosis. $\mathcal{F}$ Clin Invest 1985; 75 : $911-4$.

25 Spector W G. Immunologic components of granuloma formation. Epithelioid cells, giant cells and sarcoidosis. formation. Epithelioid cells, giant cells and sarcoidosis.

26 Lowe J R, Dixon J S, Guthrie J A, McWhinney P. Serum and synovial fluid levels of angiotensin converting enzyme in Dis 1986; 45: $921-4$

27 Goto M, Fujisawa M, Yamada A, et al. Spontaneous release of angiotensin converting enzyme and interleukin $1 \mathrm{~B}$ from peripheral blood monocytes from patients with rheumatoid arthritis under a serum free condition. Ann Rheum Dis 1990; 49: 172-6.

28 Blake D R, Unsworth J, Outhwaite J M, et al. Hypoxic reperfusion injury in the inflamed joint. Lancet 1989; 289-92. 